Egyptian Journal of Aquatic Biology \& Fisheries

Zoology Department, Faculty of Science,

Ain Shams University, Cairo, Egypt.

ISSN $1110-6131$

Vol. 24(7): $1023-1032$ (2020)

www.ejabf.journals.ekb.eg

\title{
Comparative anatomy study of teeth types in Barracauda and Tilapia fish
}

\author{
Nora Abdulaziz Aljalaud \\ Biology Department, College of Science, Imam Abdulrahman Bin Faisal University, Saudi Arabia \\ * Corresponding author: naljalaud@iau.edu.sa
}

ARTICLE INFO

Article History:

Received: Oct. 22, 2020

Accepted: Nov. 18, 2020

Online: Dec. 20, 2020

Keywords:

Nile Tilapia;

Oreochromis niloticus;

Barracauda;

Sphyraena barracauda;

Jaw teeth;

Pharyngeal teeth.

\begin{abstract}
This study investigates the general morphology and the ultrastructure of teeth types in adults of 2 fish species (the baracouda, Sphyraena barracuda and the Nile Tilapia, Oreochromis niloticus). Also, it investigates the relationship between teeth types in fish and its feeding habits, where tilapia is an herbivore, while barracuda is a carnivore. The present work has applied the anatomy of barracuda and tilapia and analyzed the types of teeth and how they work. The teeth were investigated by binocular microscope and scanning electron microscopy to determine the shape of teeth in both barracuda and tilapia; and determine the method of using these teeth in feeding. The results indicated that there is a difference between barracuda and tilapia teeth in structural morphology and type. This difference was demonstrated by virtual and microscopic examination, and this is due to the different feeding habits of both barracuda and tilapia.
\end{abstract}

\section{INTRODUCTION}

Examination of organisms feeding apparatus, especially teeth, can provide insight not only into feeding habits, but also into their ecology such as habitat distribution. Teeth represent the hardest tissue in most living vertebrates. Their main function is catching prey and mastication of food (Lubke et al., 2015). like other animals, fish have evolved to have different types and shape of teeth depending on their diets and dietary habits, also the gene regulatory network involved in tooth morphogenesis led to evolution of tooth shapes (Debiais-Thiboud $\boldsymbol{e t}$ al., 2015). There are four basic eating groups among fish: carnivores, herbivores and omnivores. Each group of fish needs to be fed in a particular way. For example, most fish that eat other fish (carnivores) have teeth that are designed to puncture, hold on to, and cut their prey whereas most fish that eat plants (herbivores) have teeth that are more suited for shredding things such as algae. Fish that eat crustaceans and mollusks have short, dense teeth; coral fish have a fine mouth with fine teeth and a sharp cutter bite coral. So the difference between the types of teeth in the 
fish is due to the mutations in the form and arrangement and places of the teeth to fit the type of nutrition (Bonato et al., 2017), and there is a system known as the teething system (Dentation). This system changes with age and dietary habits (Alsafy $\boldsymbol{e t}$ al., 2018; Woltmann et al., 2018; Elgendy et al., 2016; Bemis et al., 2005).

Barracuda found in the tropical and sub-tropical waters of the world. Barracudas feed on an array of prey including fishes such as jacks, grunts, groupers, snappers, small tunas, mullets, killifishes, herrings, and anchovies. Barracudas have a large gape and very sharp teeth, enabling them to feed on large fishes by chopping them in half, barracuda also called the "Tiger of the Sea" due to its sharp pointed teeth and strong jaws (Justin et al., 2008).

Tilapia is native to warm, fresh and brackish waters of Africa and Central America. There are nearly hundred species of tilapia and there are four most common species of tilapia which are Nile tilapia, blue tilapia, Gallilea tilapia and Mozambique tilapia. Tilapia is omnivores; feed on a wide variety of dietary sources, including phytoplankton, periphyton, zooplanktons, larval fish and detritus (Mjoun et al., 2010). The teeth of tilapia include both the sharp teeth of the jaws and teeth of the throat or pharyngeal teeth. Teeth in the pharynx are frequently associated with jaw teeth, which are situated immediately anterior to the esophagus Pharyngeal teeth and jaws in some species are involved in the processing of food, whereby it is masticated and crushed before being transported to the esophagus for swallowing (Aljalaud et al., 2017).

Thus, the present study aimed to investigate the different types of teeth in both of barracuda fish, Sphyraena barracuda and tilapia fish, Oreochromis niloticus; and to compare between their teeth types in relation to their feeding habits.

\section{MATERIALS AND METHODS}

Fishes for the study were collected from the Arabian Gulf water in Dammam city of Saudi Arabia. Four adult live specimens of each fish species of Sphyraena barracuda which belong to Family: Sphyraenidae (Fig. 1); Oreochromis niloticus which belong to Family: Cichlidae (Fig. 2). The selected fish were treated while obtaining, dissecting and disposing of their residues in accordance with international standards and regulations of the Kingdom and Imam Abdulrahman bin Faisal University in the ethics of scientific research. For the gross anatomy, the fish was photographed using digital camera; then the head of the specimens were cut from the body by using the anatomy tools; then examine the parts to be studied by the Binocular microscope which available in the research units of the Faculty of Science of Imam Abdulrahman bin Faisal University.

For Scanning Electron Microscope (SEM), the specimens of teeth were extracted from fishes, the specimens are fixed in $2.5 \%$ buffered glutaraldehyde in $0.1 \mathrm{M}$ phosphate 
buffered solution $\mathrm{pH} 7.4$ at $4^{\circ} \mathrm{C}$ for $2 \mathrm{hrs}$; washed three times with $0.1 \mathrm{M}$ phosphate buffered solution for $10 \mathrm{~min}$ each. The specimens are post-fixed in $1 \%$ osmic acid $30 \mathrm{~min}$ at $4^{\circ} \mathrm{C}$, and then washed three times with $0.1 \mathrm{M}$ phosphate buffered solution 10 min each. The specimens are then treated with $3 \mathrm{~N}$ hydrochloric acid for $10 \mathrm{~min}$ at $60^{\circ} \mathrm{C}$ to remove the mucus secretions from the tongue surface, dehydrated and specimens were dried in SPI critical point drying machine using liquid $\mathrm{CO}_{2}$. Specimens are mounted on aluminium stubs, coated with gold, then examined and photographed by using scanning electron microscope (Al-jalaud et al., 2017). This step was done at the laboratories of the Institute of Research and Medical Consultancy at Imam Abdulrahman bin Faisal University.

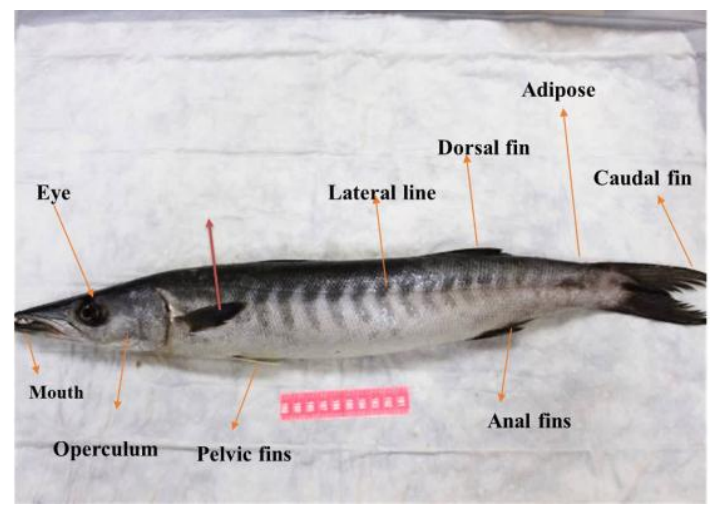

Fig. (1): Lateral view of barracuda fish

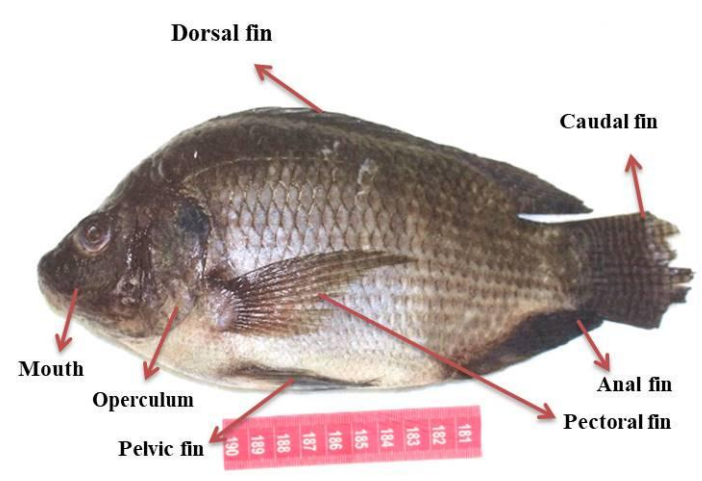

Fig. (2): Lateral view of tilapia fish

\section{RESULTS AND DISCUSSION}

\section{General morphology of fish teeth:}

\subsection{Sphyraena barracuda:}

The great barracuda has a slender long tubular body, that is round in the midsection characterized by fins were raised towards the caudal fin. Dark gray above it, fading to silver and white below it, usually dark spots on its underside, sometimes with darkish stripes on its upper side. The top of the head between the eyes is nearly flat (Fig.1) and the mouth is large, with two rows of conical sharp teeth which are unequal in size and a projecting lower jaw, the lower jaw protrudes beyond its upper jaws (Figs. 3\&4).

The great barracuda fish has a row of small sharp teeth along the outside of the jaw with a larger set of dagger-like teeth within these. The closely set teeth are flattened and triangular with sharp edges used to tear the flesh of prey. Long needlelike teeth fit into their own holes in the opposing jaw, allowing the great barracuda to close its mouth 
formidable array of strong and long canine sharp teeth like piranhas teeth on the jaws (Figs. 3 - 5). The previous description agrees with (Justin et al., 2008; Aljalaud et al., 2017). This variation in teeth is somewhat similar to the description of Scyliorhinus canicula teeth (Debiais-Thiboud et al., 2015). They found that the adult jaw teeth of the S. canicula are systematically organized; also the teeth were arranged in families with the older tooth locally in an oral position while the newly developed teeth (alternating alternate teeth were observed) were found in a more cavernous position.

\subsection{Oreochromis niloticus:}

Tilapia typically has laterally dark compressed, deep body; it has a long dorsal fin and a lateral line which often breaks towards the end of the dorsal fin. Its mouth is protractible, usually bordered with wide and often swollen lips (Figs. 2\&6).

Tilapia fish are primarily herbivorous or detritus feeders. Their teeth tend to be coarser and sharp. This includes both the upper and lower conical teeth of the jaws (Figs. 6 - 8). This description agrees with many authors (Geerinckx et al., 2007 and Sahara $\boldsymbol{e t}$ al., 2018) in herbivore feeding habit of fish. Also, it agrees with Alsafy et al. (2018) in their description on the upper and lower pharyngeal teeth of Bagrus Bayad which is carnivorous nature. They found that the upper teeth arranged into two oval prominences while the lower ones transformed into two triangular areas. Bowen (1982) reported that the jaw teeth are employed by Tilapia species to bite and tear plant material.

Teeth on the pharyngeal bones of $O$. niloticus, which have the same size and shape, were found to be fine, thin, pointed and lodged on the pharyngeal bones (Figs. 7 \& 8). The pharyngeal teeth of the phytoplanktivorous tilapia, such as Sarotherodon esculentus, are fine, thin and hooked on the pharyngeal bones, whereas these of macrophyte feeders, such as $T$. rendalli, are coarse and robust (Caulton, 1976). Fryer \& Iles (1972) reported that Tilapia have pharyngeal teeth which are varied in configuration from one tilapia species to another, to suit the different diet preferences.

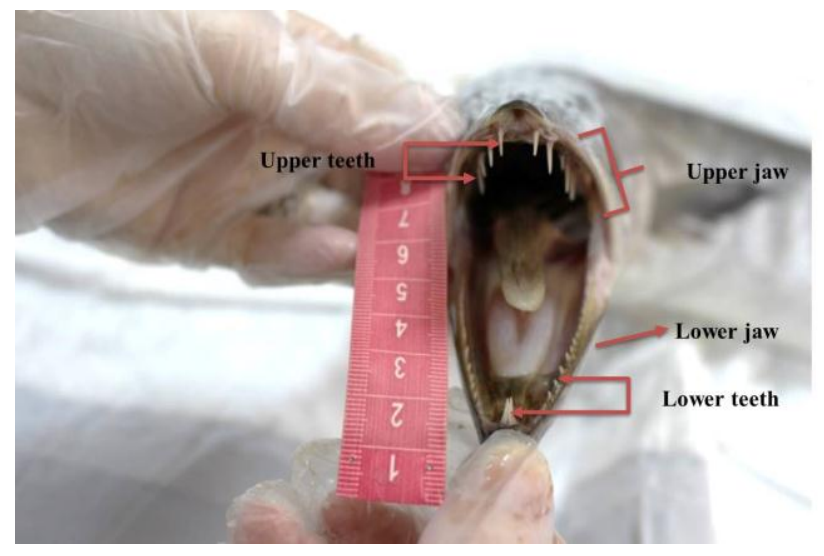

Fig. (3): Anterior view of barracuda fish

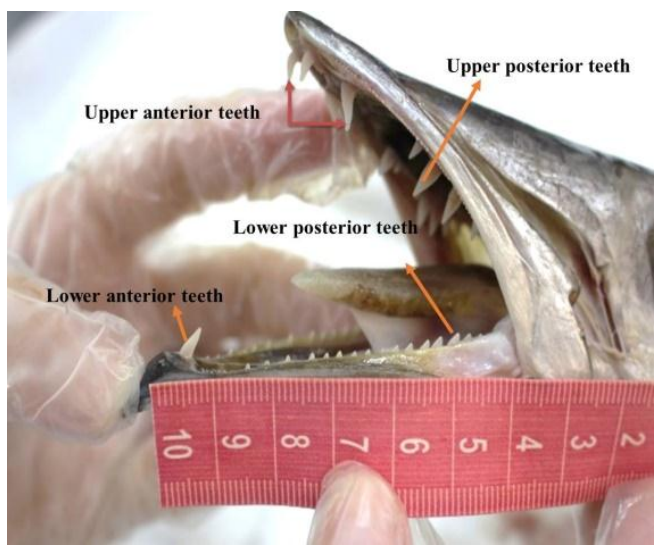

Fig. (4): Lateral view of barracuda fish 


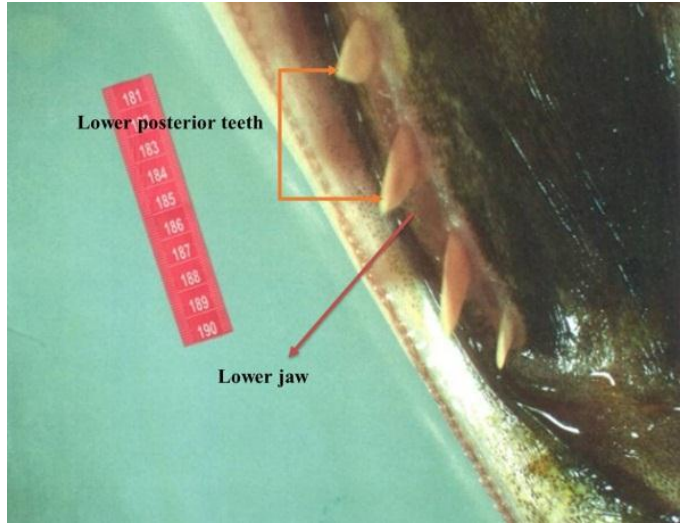

Fig. (5): Lateral view of barracuda fish

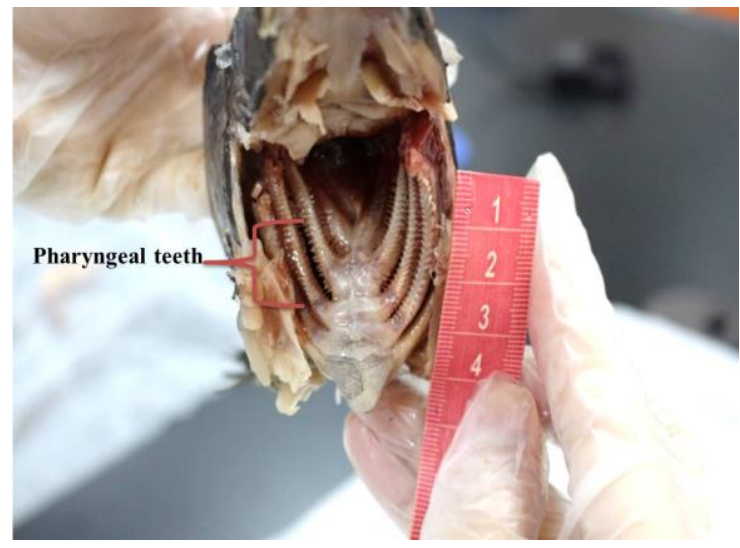

Fig. (7): Ventral view of tilapia fish

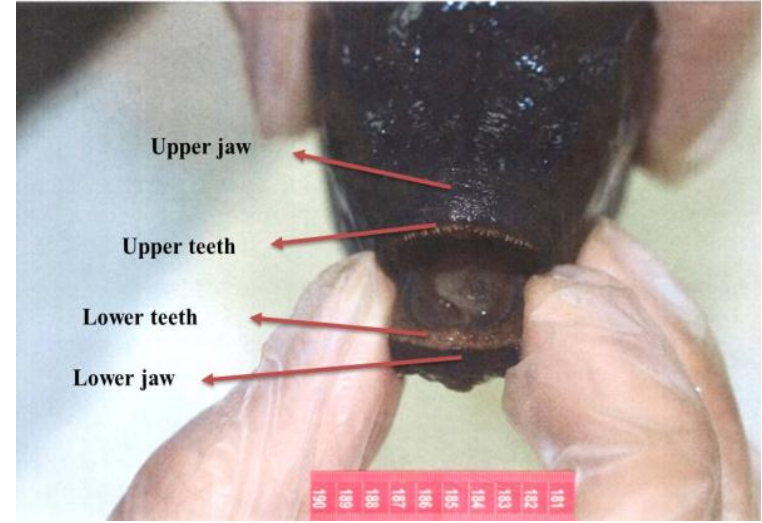

Fig. (6): Anterior view of tilapia fish

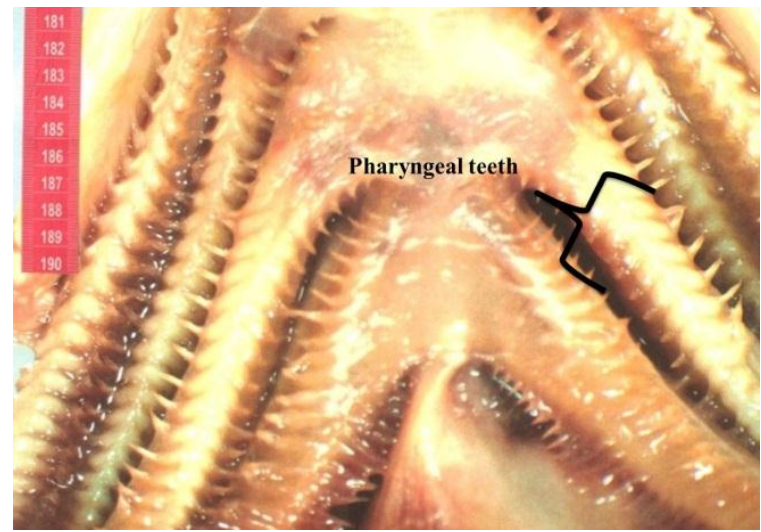

Fig. (8): Internal view of tilapia fish

\section{Scanning Electron Microscopy of fish teeth:}

\subsection{Sphyraena barracuda:}

The examination of barracuda fish teeth by the scanning electron microscopy showed many types of teeth adapted to the capacity and varieties of feeding. The upper teeth of barracuda with different magnification show the two strong and sharp incoming teeth, it is pointed, flattened with triangular edges (Figs. 9 \& 10). This description agrees with Bemis et al. (2005), in their description of the blue fish teeth.

The lower anterior teeth of barracuda with different magnifications showed the strong and very sharp teeth like the hook. Also showed a visible part of the soft enamel texture which forms a thin layer covering the surface of the outer tooth (Figs.11 \& 12). This description agrees with Manzanares et al. (2014). The lower posterior side of the barracuda teeth showed series of similar teeth in size and shape. With different 
magnifications, the enamel layer that covers the edge of the teeth was observed and it gives the teeth a pointed edge and sharpness (Figs. 13 \& 14).

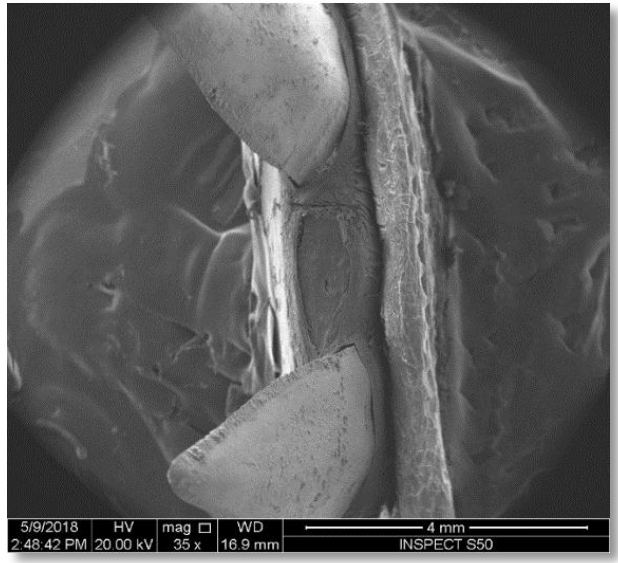

Fig. (9): SEM of upper anterior teeth of barracuda; $x 35$

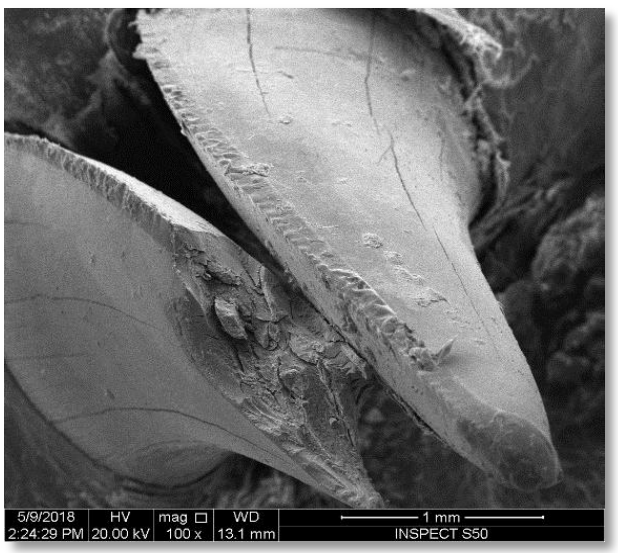

Fig. (11): SEM of lower anterior teeth of barracuda; $x 100$

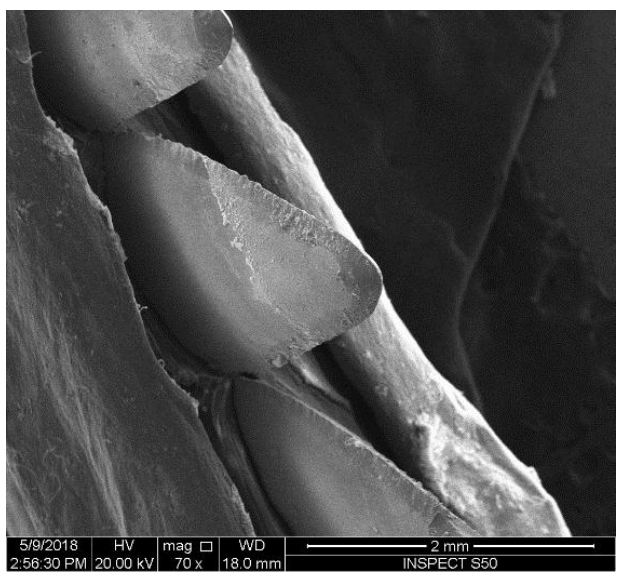

Fig. (13): SEM of lower posterior teeth of barracuda; $x 70$

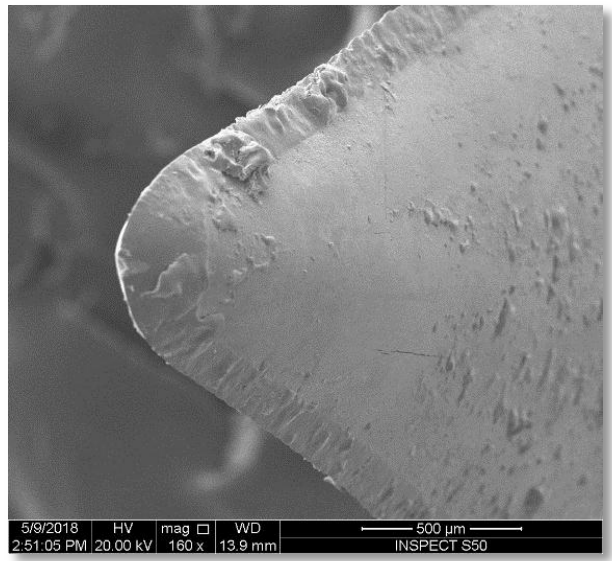

Fig. (10): SEM of upper anterior teeth of barracuda; $x 160$

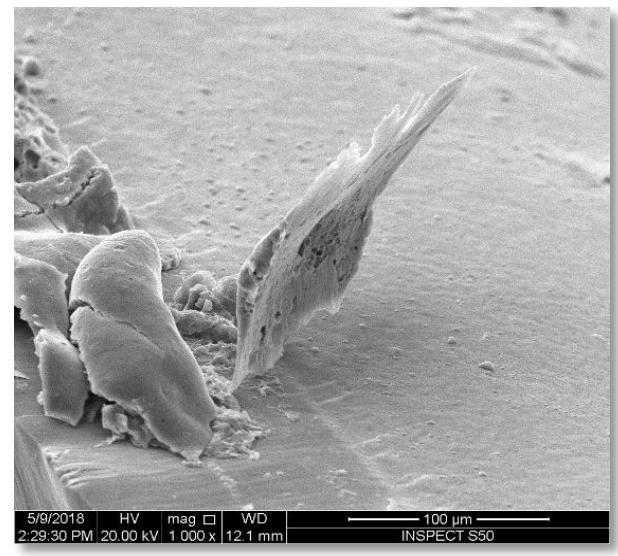

Fig. (12): SEM of lower anterior teeth of barracuda; $x 1000$

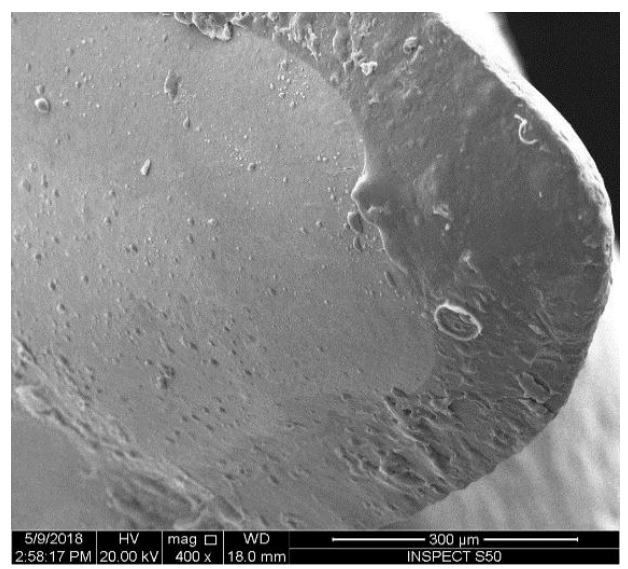

Fig. (14): SEM of lower posterior teeth of barracuda; $x 400$ 


\subsection{Oreochromis niloticus:}

The examination of Tilapia fish teeth by the scanning electron microscopy showed that it has two types of teeth: jaw teeth and pharyngeal teeth. The jaw teeth are small, unicuspid, bicuspid or tricuspid structures; arranged in one to five rows and flattened distally to form blades that can be used as scrapers. The scanning electron micrograph represents the upper tilapia teeth are duality at the tip of a rod-like structure, the size of which perfectly matches the size of herbal algae. The teeth form a single overlapping row along the front edge of the upper jaw. In addition, teeth including series of developing teeth and fully functional teeth are longitudinally organized into multiple rows under the soft tissue (Figs. 15\&16). This description agrees with Geerinckx et al. (2007).

The pharyngeal teeth of tilapia are fine, thin and hooked on the pharyngeal bones. oral cavity are represents with two pads, appear as V-shaped at the midline of buccal cavity, they are studded with several rows of villiform teeth with different size, pointed and arranged closely together, the teeth which situated toward the periphery of the pads are large, very strong, all these teeth oriented backward to the esophagus entrance (Figs. 17\&18). SEM observations agree with Aljalaud et al. (2017).

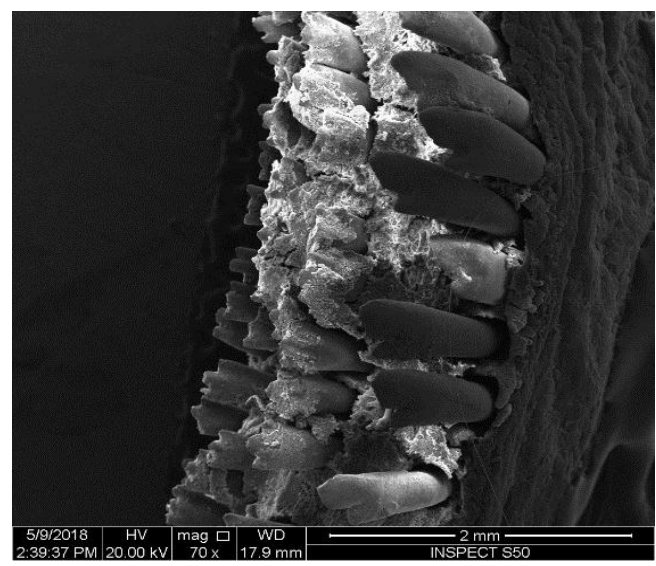

Fig. (15): SEM of upper teeth of tilapia; $x 70$

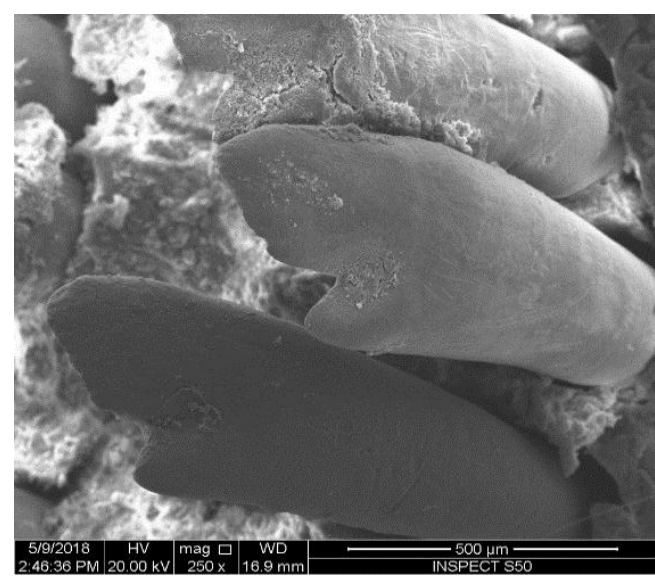

Fig. (16): SEM of upper teeth of tilapia; $x 250$ 


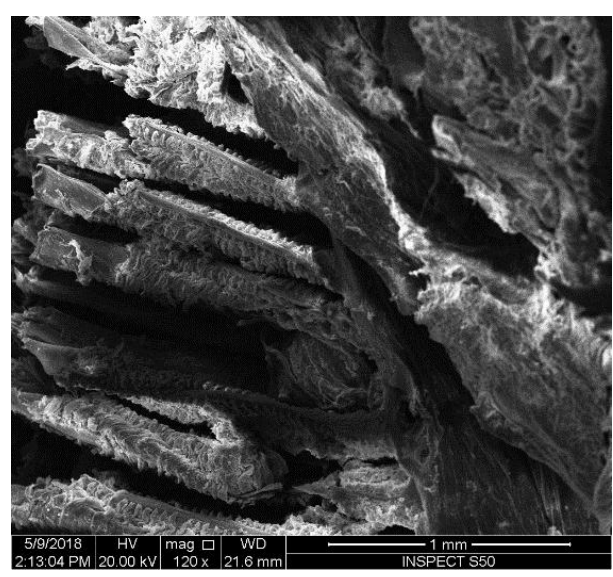

Fig. (17): SEM of pharyngeal teeth of tilapia; $x 160$

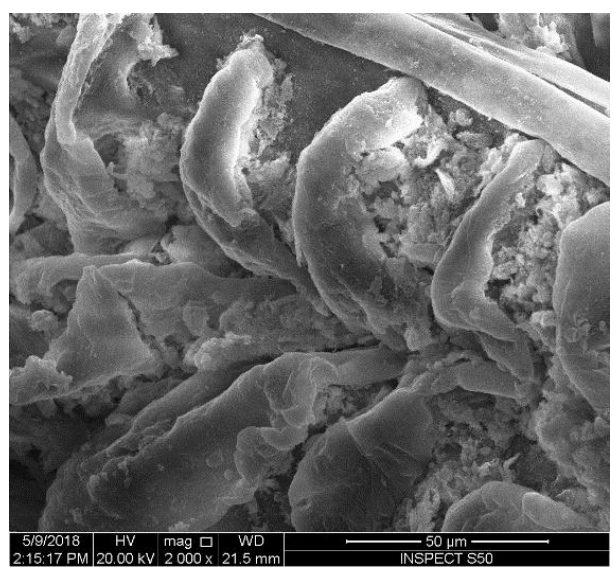

Fig.18 SEM of pharyngeal teeth of tilapia; $x 2000$

\section{REFERENCES}

Aljalaud, N. A.; Abou-Zaid, D. F. A. and Salem, S. B. (2017): Morphological specializations of the teeth of Red Sea fish in relation to feeding habit. Egyptian Journal of Experimental Biology, 13 (2): 329 - 337.

Alsafy, M. A. M.; Bassiony, N. F. and Hanafy, B. G. (2018): Gross Morphology and Scanning Electron Microscopy of the Bagrus Bayad (Forskal, 1775) Oropharyngeal Cavity with Emphasis to Teeth-Food Adaptation. Microscopy Research and Technique, 81 (8): 878-886.

Bemis, W. E.; Giuliano, A. and McGuire, B. (2005): Structure, attachment, replacement and growth of teeth in bluefish, Pomatomus saltatrix (Linnaeus, 1766), a teleost with deeply socketed teeth. Zoology, 108: 317-327.

Bonato, K. O.; Burress, E. D. and Fialho, C. B. (2017): Dietary differentiation in relation to mouth and tooth morphology of a neotropical characid fish community. Zoologischer Anzeiger, 267: 31-40.

Bowen, S. H. (1982): Feeding, digestion and growth -qualitative considerations. In: Pullin, R. S. V. and Lowe-Mcconnell, R. H. (Eds.). The Biology and Culture of Tilapias. ICLARMCon. Proc. 7: ICLARM, Manila, pp: 141-156.

Caulton, M. S. (1976): The importance of pre-digestive food preparation to Tilapia rendalli Boulanger when feeding on aquatic macrophytes. Transactions Rhodesian Sci. Association, 57: $22-28$.

Debiais-Thiboud, M. T.; Chiori, R.; Enault, S.; Oulion, S.; Germon, I.; Martinand-Mari, C. M.; Casane, D. and Borday-Birraux, V. (2015): Tooth and scale morphogenesis in shark: An alternative process to the mammalian enamel knot system. BMC Evolutionary Biology, 15 (1): 292-307.

Elgendy, S. A. A.; Alsafy, M. A. M. and Tanekhy, M. (2016): Morphological Characterization of the Oral Cavity of the Gilthead Seabream (Sparus Aurata) with 
Emphasis on the Teeth-Age Adaptation. Microscopy Research and Technique, 79 (3): 227-236.

Fryer, G. \& Iles, T. D. (1972): The Chichlid Fishes of the Great Lakes of Africa: their Biology and Evolution. T.F.H. Publ., Neptune City, New Jersey.

Geerinckx, T.; De, J. P. and Adriaens, D. (2007): Morphology and development of teeth and epidermal brushes in loricariid catfishes. J. of Morphology, 268 (9): 805814.

Justin, R. G.; Aaron, N. R. and Mark, W. W. (2008): Functional morphology of bite mechanics in the great barracuda (Sphyraena barracuda). Zoology, 111 (1):16-29.

Lubke, A.; Enax, J.; Loza, K.; Prymak, O.; Gaengler, P.; Fabritius, H. O.; Raabe, D. and Epple, M. (2015): Dental lessons from past to present: ultrastructure and composition of teeth from plesiosaurs, dinosaurs, extinct and recent sharks. Royal Society of Chemistry Advances, 5 (76): 61612-61622.

Manzanares, E.; Pla, C.; Martinez, C. P.; Rasskin, D. and Botella, H. (2014): The enameloid microstructure of euselachian (Chondrichthyes) scales. Paleontological Journal, 48: (10): 1060-1066.

Mjoun, K.; Rosentrater, K. and Michael, L. B. (2010): Tilapia: Environmental Biology and Nutritional Requirements. South Dakota State University. 7 pp.

Sahara, N.; Moriyama, K.; Iida, M. and Watanabe, S. (2018): Fate of worn-out functional teeth in the upper jaw dentation of Sicyopterus japonicus (Gobioidei: Sicydiinae) during tooth replacement. The Anatomical Record Advances in Integrative Anatomy and Evolutionary Biology, 301(1):111-124.

Woltmann, I.; Shkil, F.; Huysseune, A. and Witten, P. E. (2018): Supernumerary teeth in the pharyngeal dentation of slow-developing zebrafish (Danio rerio, Hamilton, 1822). J. of Applied Ichthyology, 34:455-464. 


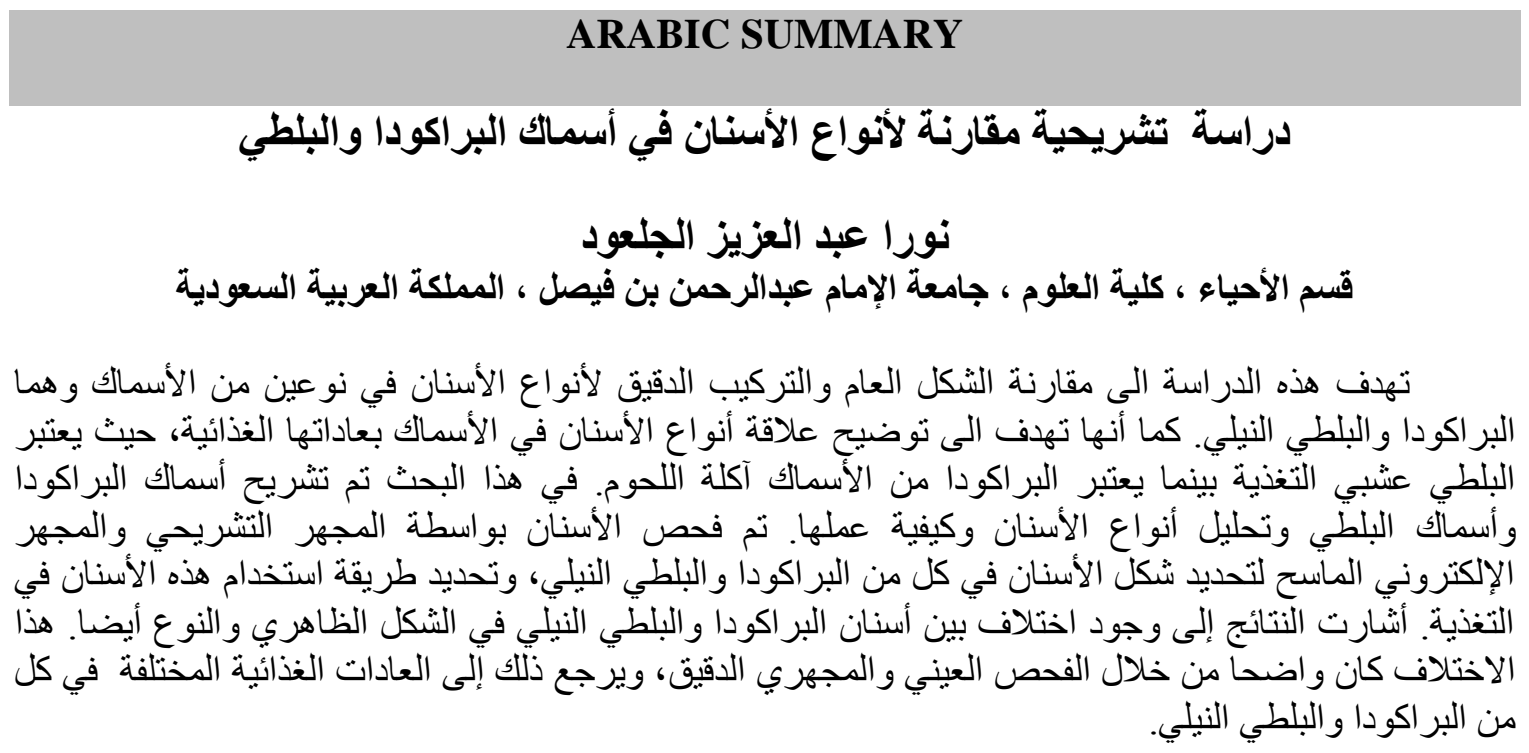

